\title{
On the Radioactivity of Fiestaware
}

\author{
Eric B. Norman \\ Nuclear Science Division \\ Lawrence Berkeley National Laboratory \\ March 13, 2002
}

In order to investigate the question of the radioactivity of Fiestaware, I borrowed from Lee Schroeder 9 small Fiestaware plates of different colors. Eight of these plates are shown in the photograph below. The ninth was a "rose" colored plate that I got from Lee a few days after the first batch. I also borrowed three pieces of Fiestaware from Christine Donahue: a yellow teapot, a light-yellow creamer and a light-yellow dinner plate. I counted each sample individually for 5 minutes using a shielded $110 \mathrm{~cm}^{3}$ high-purity germanium detector in Room 131 of Bldg. 88. I also obtained a room background spectrum for 5 minutes.

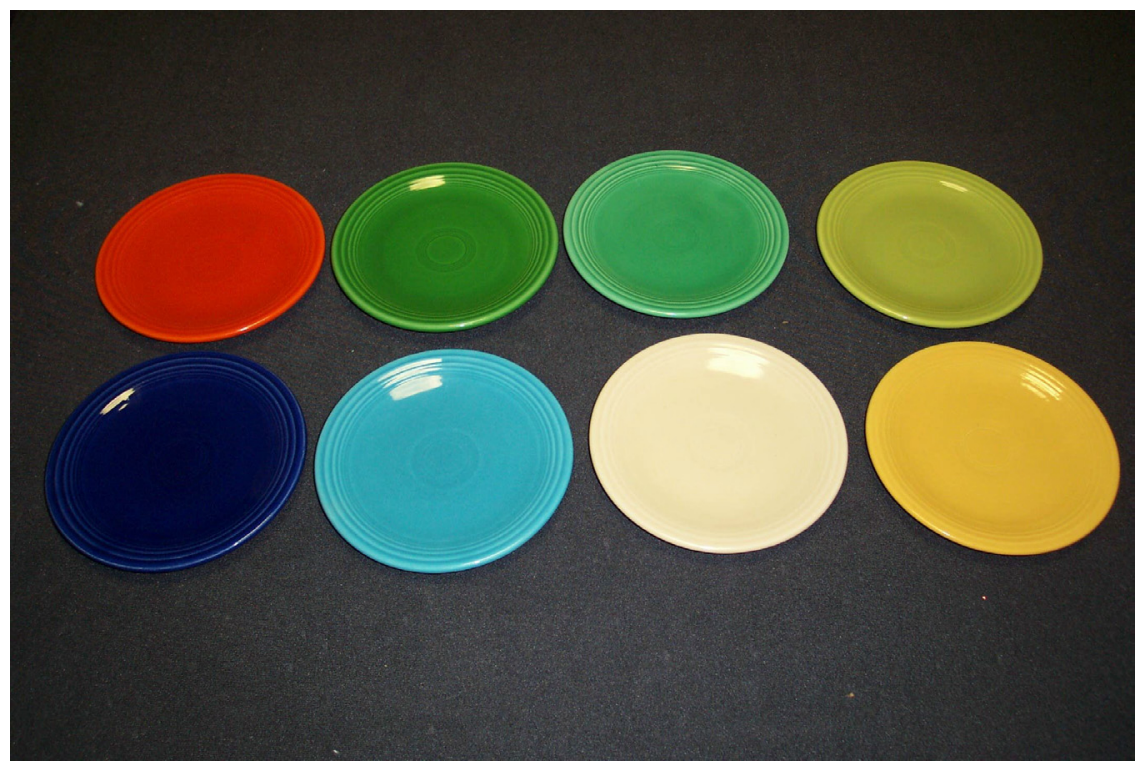

Figure 1. Eight of the nine Fiestaware plates that were studied.

The only plate that showed a measurable net activity above room background was the orange colored plate. The background subtracted spectrum obtained for the orange plate is shown below. The gamma-ray peaks seen in this spectrum are attributable to the decay of uranium isotopes and their daughters. This result is not surprising, because the orange color of the plate is due to the presence of uranium oxide in the glaze. I also counted the radiation from this orange plate using several other types of counters. Using an LBNL alpha counter, I 
measured 6000 counts per minute of alpha activity when the probe was placed directly on the surface of the plate. A Ludlum sodium iodide monitor registered approximately $50 \mu \mathrm{R} /$ hour on contact, while a BICRON ionization chamber measured $6 \mathrm{mR} /$ hour with its window open and less than $0.1 \mathrm{mR} /$ hour with the window closed.

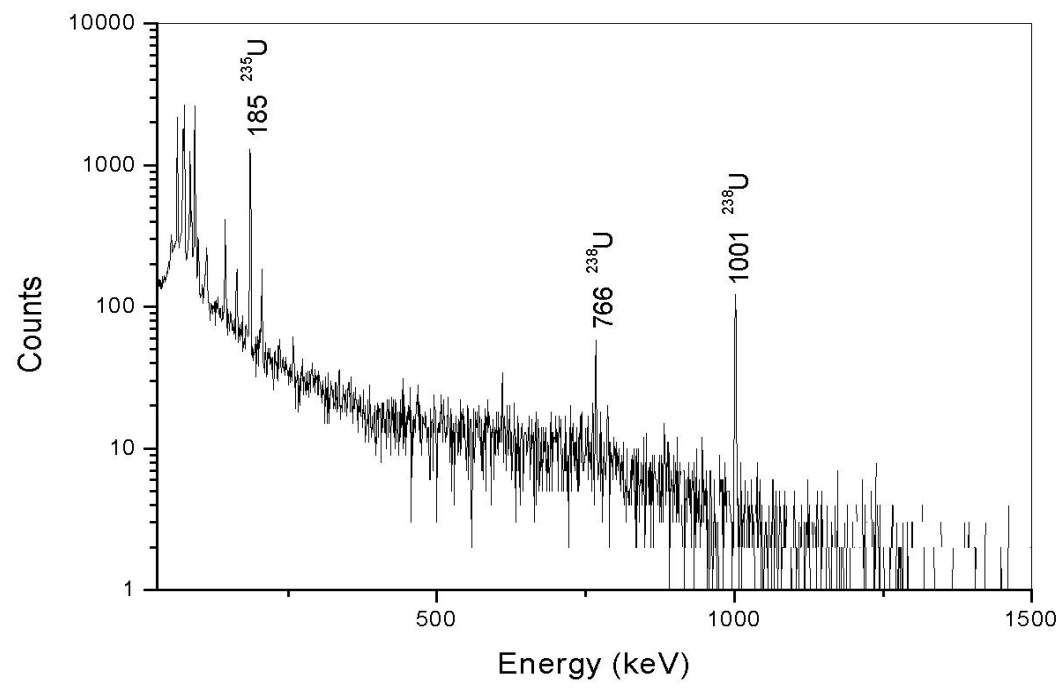

Figure 2. Background-subtracted gamma-ray spectrum observed from the orange Fiestaware plate.

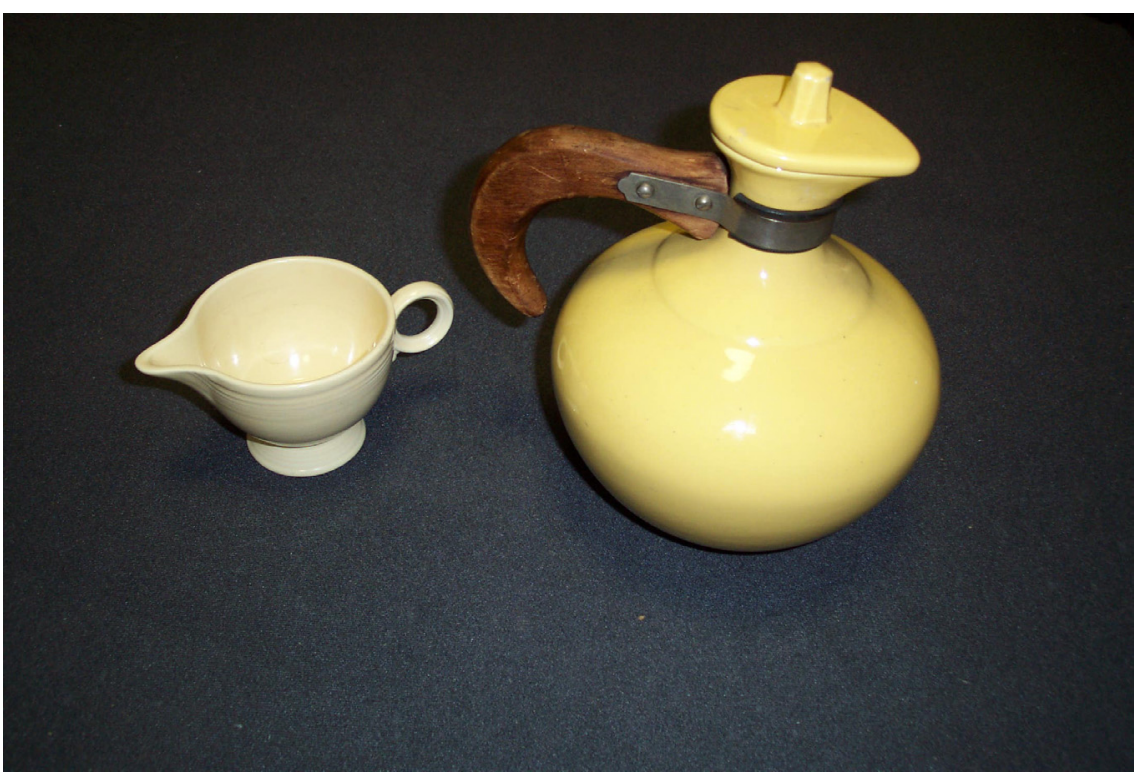

Figure 3. Fiestaware teapot and creamer that were studied. 
The gamma-ray spectra observed from the teapot, creamer, and dinner plate all also showed the presence of uranium. Of these three pieces, the teapot had the highest level of activity, but this level was approximately one quarter as large as that seen from the orange plate described above.

The only gamma rays observed from any of these pieces of Fiestaware are produced by the decays of uranium isotopes and their daughters. If there is any thorium present in these pieces, it must be at a very low level compared to that of the uranium. None of the observed radioactivity levels are very high and should not be cause for alarm. The uranium activity is firmly attached to the Fiestaware and is not likely to come off. Nevertheless, I don't think I would want to routinely eat salad off the orange plate or drink tea from the yellow teapot! 